\title{
Brief analysis about modern simple style in interior design Liwei Chen $^{1}$ \\ ${ }^{1}$ Environmental Art Design, Hebei Institute of Fine Arts, XinLe, ShiJiaZhuang, China. Chenliwei008@163.com
}

Keywords: inimalist style; Interior design; Modern design techniques

\begin{abstract}
Since 2005, the market of domestic design has been fully liberalized, foreign designers poured into the domestic, we have been take the competition pressure both from domestic and international. Foreign design enter into China, let the domestic design industry has get into elimination period, this situation can bring us the advanced concept of material, as well as give us brought a lot of forward momentum. Although not necessarily each foreign designers get to China are stronger than us, but there have no doubt about their overall height. Market capacity is limited, the enter of foreign design certainly will bring impact to us, for example, they will bring change of the pattern of fundamental. The designers who originally do the high-class design then may now can only turn to do the low-end. The first to bear the brunt is who originally do the low-end ,the competition pressure they undertake will increase, maybe they will seek for other jobs. But the foreign design will not choose long-term roots in the Chinese market, for they are not very understanding national conditions of China, most of them will choose get cooperation with design company. After some time, they also face the elimination period, the market also will eliminate someone who is not fantastic. So the entering of foreign designers will urge the market grow towards more standardized direction, and we need to absorb foreign advanced design concepts and production of materials, relying on our own understanding of the Chinese design industry, take the essence, making our design industry grow and develop to the world stage.
\end{abstract}

\section{Introduction}

In interior design, home design is very common and increasingly universal. Regardless of the city or the countryside, people are all in the pursuit of higher living comfort. The minimalist style in the current design have been loved most, and it's now popular style of interior design tendency. He nique performance method and rich connotation interpret a new modern home design concept $o$ people. In the modern decoration, simple and minimalist pursuit of brief. This paper will first gives a brief description of the minimalist style, and then from design features of minimalism style characteristics, minimalism style unique design skills, minimalist style in the interior of the specific application and so on to give a summary elaboration.

\section{The manifestation of the beauty of interior design form}

Modern life rhythm accelerate continue, people in the life and work of the troubles hope to get a simple, quiet living environment. Based on the influence of the factors, people in living gradually abandon complex style, showing a trend of simplification, especially in the modern living environment, room is the best place for people to relax, its design style and effect directly affects the people's life quality and mental health. Therefore, minimalist style gradually adapted to the needs of people living conditions. Interior design is under the premise of people-oriented first and then meet the practical function, use of formal language to express the subject matter, themes, emotions and moods, forms of language and formal beauty can be represented by the following ways.

One. Contrast. The contrast is the basic skills for shape of art design. Contrast is called as making two different things, such as color, shape to compare. Such as black and white, big and small, new and old, etc. Take two apparently opposing elements in the same space, through the 
design, to make the different elements both antagonistic and harmonious, contradiction and unity, seeking complementary and meet results.

Two. Harmony. The meaning of harmony contains harmonious. Means under the premise of meeting the functional requirements, the combination of variety of indoor objects such as shape, color, light, make the combination get coordinated and unified Whole harmony can also be divided into the harmonious about environment and the shape, harmony of texture, color, style and so on. Enable people get psychological quiet, calm and satisfaction in the visual.

Three. Symmetry. Symmetry is the formal beauty of the traditional techniques, is the earliest available beauty skill . The symmetry is also divided into absolute symmetry and relative symmetry. Absolute symmetry conclude up and down, right and left, the same shape, same color, same homogeneous . In interior design usually use relatively symmetrical. The symmetry gives the order, the gravity, the neat and the harmonious beauty feeling.

Four. Equilibrium. The Golden Rooster independent single leg, actors tightrope. Equilibrium means enjoy visual for people from force equilibrium, make people obtain the visual psychological equilibrium, the equilibrium is under axis, center point ranging from the shape and the equivalent form, component, color configuration.

Five. Levels. A decorative design, should distinguish levels, so that the screen has the depth, and breadth. The lack of hierarchy will making eyes feel mediocre, interior design should pursuit of space level sense. Such as color from warm to cold, from light to dark, texture from simple to complex, modeling from big to small, from square to round, the quality from single to variety and so on. Hierarchical change can obtain extremely rich visual effect.

Six. Echo. In the interior design, ceiling, ground, desktop and other parts should using the technique of echo, physical treatment, play the corresponding role. Echoes belongs the balanced beauty form, is commonly used method in a variety of artistic practices.

Seven. Continuation. Continuous refers to the extension. People often use "image" refers to all the appearance of the object shape. If an image continues to extend from up to down, or left to right is the continuation. Continued use of this technique in space, make the space take outspread feeling, and even can deepen people's impression of the scene focus on the environment.

Eight. Simple. Concise or brief. Refers to the indoor environment have no gorgeous modification and superfluous appendages. With the principle of concise, reduce interior decoration to a minimum. Consider less is more, concise is rich . Brevity is of one particular approach advocated in interior design, is also a very popular trend in recent years.

Nine. Unique. Unique also known as specificity. Unique is to break the original rules, attract people's attention with new and different. In nature, "a little green leaves red, green in the desert", is unique manifestation. Unique is result from comparison. Resulting in the unique foil, and there is mutual comparison. In the interior design there was a breakthrough in high esteem imagination, to create a personality and characteristics.

Ten. tone. Color is one of the important factors in the design arts. Different colors can cause different color sense of vision. Such as red, orange, yellow making prople feeling very warm, known as warm system colors.Green, blue making people feel cold, called cool system colors. In the interior design, you can use all kinds of color composition, there are many kind of colors, and can be summarized as "the same tone, same class tone, contrast tone", we can use flexibly according to different environment.

Interior design as the category of three-dimensional space design has close contact with architectural design. They are indivisible. Overall, the interior design has the following characteristics: First of all, interior design has category on the human body . Temperature and other factors in the lighting environment constitute physiological environment . And the size and shape of the interior interface, pattern, color, texture has became more and more influence on people's psychological environment. Two kinds of environmental impact and interaction, together formed the most closely environment. Secondly, it embodies the design aesthetics of life. The design method and vocabulary is not only confined to the beauty of space shape, also reflected in the decorative beauty. The interior space has become a comprehensive reflection of space art, an ideal 
place for decorative art and other art. Third, problems obvious for update the change of indoor function and technology. The indoor environment update cycle becomes shorter Than the main building space, but rhythm be more rapid; indoor design style changes are more active, due to changes of lifestyle caused by the indoor space design requirements, design concept also need to has certain forward-looking. And again, with a high technology and added value. Modern interior design of new indoor environment, often has new requirements in computer control, automation, and so on .So that the indoor equipments, electric appliances and communication have a higher technological content. In addition, the modern interior design and the added value of the product with increasing technology content increased. Finally, the design has obvious personality. The interior design can comprehensively reflect the user's aesthetic taste and life attitude .The interior design display space for development due to user’s personality special pursuit.

\section{Modern minimalist style}

One. Brief introduction of modern simple style. For concise style of the interior environment design, there have no consistent definition and evaluation in social. Different people for contemporary and contracted style have different understanding. Some people think that simplicity is the delete extra symbols to get rid of the rest part, but also some people think simplicity is abandoned the tedious details, and the remaining part of the essence of things. Although the people hold different minds for contemporary simple style, but is same in essence of consciousness. that's require to eliminate redundant elements, by as little as possible ways and means of things of sense perception and creation, reflected in a simple form to the essence of things.

Two. Connotation of modern simple design. First is quantity simplicity. In modern interior environment design, exclusive or change the a large number of modeling contents, and then rearrange the contents, to form a single arrangement rules, which is called the quantity simple. All kinds of simple geometry constitute the entire indoor environment, which in unified and interest. Second is style simplicity. Cumbersome useless details should be avoided in the interior simple design; extracted the artistic elements and the pure elements of life; should safeguard the hierarchy, integrity, fluency and naturalness indoor; form a harmonious, natural and unified aesthetic feeling, reflecting a minimalist art atmosphere. Third is quality simplicity. In fact, the simplicity design means the simple from quality. Constituent elements in the indoor environment is not reduced, just reorder according to a more scientific and reasonable methods and rules, let these elements from disorderly to orderly, and can satisfy people's aesthetic needs. Why simple home design style be approved by the people for long and become beautiful home landscape One reason can be traced back from the history of interior design, although the interior design industry of our country developed rapidly, but still far behind situation. At the beginning of the eighties of the 20th century, with the reform and opening up, a large number of star hotel famous in domestic construction, decoration engineering most undertake monopoly by Hong Kong, they bring a rich, luxury, cumbersome business style, attracted by Chinese. So, the domestic decoration market, decoration, decoration style is dominated by this style. Whether the hotel, office buildings, shopping malls or Home Furnishing, all order to cover the building body by this style package. Vulgar decoration engineering spend a lot of money from the ignorant investors. The luxurious thick decoration,the "five-star" decoration of the house, just to meet the vanity for rich, waste money in this country, also caused the spirit garbage in interior design. so people expect correct and desirable life style to interpret the true meaning of interior decoration design. So simple design walking toward the concise style of development.

Three. Features of simple style design. The features of minimalist style design refers to reduce the elements about color, lighting, raw materials to the minimum extent. But have high requirements about the texture ,quality of color. Therefore, the simple style space is usually very subtle, often can achieve remarkable visual effect. Artistic creation should be concise and not be tedious. It should be reserved and not be exposed. These words are the most incisive elaborate introduction about simple. But simplicity is not simple, simple is the essence screening out from continuous combination of excellent quality. highly summarized in abstract form promote from the 
popular object shape. It is likely to use new materials, new technology, new methods unified with new ideas, new concepts, achieve people-oriented state. Nor is the lack of simple design elements, it is a higher level of creative realm. In the interior design. It don't give up the original architectural space rules and simple, to do any decoration on the construction, but in the design of more emphasis on function. Emphasis on the integrity of the structure and form.

Four. Techniques of minimalist style design. People have a deeply liking for simplicity, but little was known about the simplicity techniques. In this regard, I have summarized. First is clear lines. Minimalist furniture is usually have simple lines, except from the cabinet have simple linear, sofa, bed, table, also as a straight line, without too much curve, simple shapes, rich in design or philosophy means, no exaggeration. Second is monochrome color. Black and white is the representative color of minimalism , and gray, silver, beige color, no stamp, no totem .They brings another low-key sense of serenity. Calm, restrained. Third is materials diverse. Wooden, leather is the basic material of furniture, and in the minimalist furniture, can see the new materials of modern industry, such as aluminum, carbon fiber, plastics, high density glass, add various possibilities for furniture, such as waterproof scratch resistance, light weight and small volume. Fourth is strong designed function. Although the lines and color is simple, but minimalist furniture function is not simple, such as the chair, The minimalist chair can also free to adjust the height and shape change; frame can be open to a storage box.

Five.Simple style in the indoor application. Concise style in indoor use largely reflected in the use of materials, because all of the indoor space is composed by different materials. To show the different idea through the material. To show the different decoration effect by material. It's not the material itself account, but the use of specific performance of the internal force about various materials. Such as the essence of wood make people feel its simple and unadorned, but the same wood processed by different surface will produce different visual effects. Coarse graining makes people feel old, rough, smooth wood make people feel elegant, fine and concise. Different style, different space need different materials. In addition, only need to produce contrast from different texture, color, area of materials in unity can show rich material nature beauty, meet the needs of people's visual and tactile. For example: roomwill soon be full of fun if put a soft gray brown wool carpet This is a era of diversification. The prosperity and development of the modern architecture bring the great opportunity to interior design, and now cultural exchanges in the world generally bring great changes about aesthetic thought. People become more open, and this will give greater imagination space and more freedom to designers. It's not a long time that the simple decoration prevent in China, but it has been leading the trend of the decoration industry, has become an important manifestation for pursuit of the contemporary modern style. in the cold hardwood floor.

\section{Reference}

[1]: Zhang Yiman. Interior design style and genre [M]. China Building Industry Press. 2006.09.

[2] Sheng Zhongyi. Modern interior design and lighting materials [A].2012 Conference of international modern packaging Symposium. collection of essays. [C], 2011.

[3] Gao Cuiping. The extraction and application of symbol in interior design [A].Proceedings of the 2008 International On Industrial Design Conference (Volume 1) [C], 2009.

[4] Lu Jie, Zhang Pingfan. Color psychology design of university, [A]. Proceedings of the 2011. InternationalConference on Industrial Design \& The 11th China Industrial Design Annual Meeting(Volume 2/2)[C], 2011. 